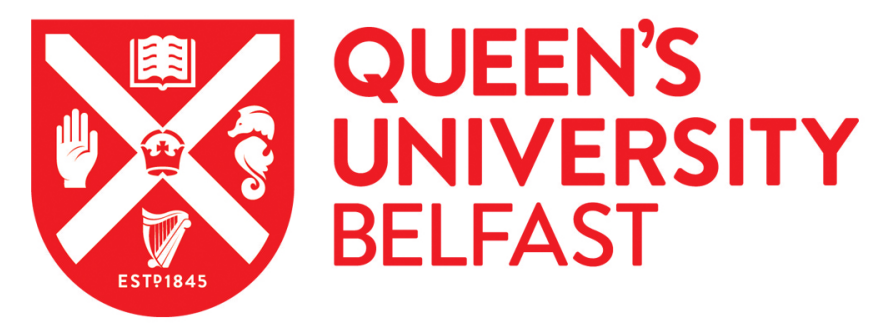

\title{
Spatial distribution of PAHs in a contaminated valley in Southeast China
}

Xing, W. Q., Luo, Y. M., Wu, L. H., Song, J., Qian, W., \& Christie, P. (2006). Spatial distribution of PAHs in a contaminated valley in Southeast China. Environmental Geochemistry and Health, 28(1-2), 89-96.

https://doi.org/10.1007/s10653-005-9017-x

\section{Published in:}

Environmental Geochemistry and Health

\section{Queen's University Belfast - Research Portal:}

Link to publication record in Queen's University Belfast Research Portal

\section{General rights}

Copyright for the publications made accessible via the Queen's University Belfast Research Portal is retained by the author(s) and / or other copyright owners and it is a condition of accessing these publications that users recognise and abide by the legal requirements associated with these rights.

Take down policy

The Research Portal is Queen's institutional repository that provides access to Queen's research output. Every effort has been made to ensure that content in the Research Portal does not infringe any person's rights, or applicable UK laws. If you discover content in the Research Portal that you believe breaches copyright or violates any law, please contact openaccess@qub.ac.uk. 


\title{
Spatial distribution of PAHs in a contaminated valley in Southeast China
}

\author{
Weiqin Xing ${ }^{1}$, Yongming Luo ${ }^{1,3}$, Longhua $\mathrm{Wu}^{1}$, Jing Song ${ }^{1}$, Wei Qian ${ }^{1}$ \& Peter Christie ${ }^{2}$ \\ ${ }^{1}$ Soil and Environmental Bioremediation Research Center, State Key Laboratory of Soil and Sustainable \\ Agriculture, Institute of Soil Science, Chinese Academy of Sciences, Nanjing 210008, China \\ ${ }^{2}$ Agricultural and Environmental Science Department, Queen's University Belfast, Newforge Lane, \\ Belfast BT9 5PX, UK \\ ${ }^{3}$ Author for correspondence (e-mail: ymluo@mail.issas.ac.cn)
}

Key words: distribution, homologue, PAHs, smelting, soil utilization, Southeast China

\begin{abstract}
A survey was conducted on the accumulation and spatial distribution of PAHs in surface soils under different land use patterns in a valley in the Yangtze Delta region with an area of $10 \mathrm{~km}^{2}$ containing 15 small copper- and zinc-smelting furnaces. Sixty-five topsoil $(0-20 \mathrm{~cm})$ samples were collected and 16 PAHs were determined. The average amount of all the 16 PAHs ranged from 0 to $530 \mu \mathrm{g} \mathrm{kg}^{-1}$ (oven dry basis), with a mean concentration of $33.2 \mu \mathrm{g} \mathrm{kg}^{-1}$. Benzo[a]pyrene and indeno[1, 2, 3, -cd]pyrene were the two main PAHs present at high concentrations, while pyrene and fluorene had very low concentrations. PAH concentrations were higher in uncultivated than in cultivated soils, and areas of woods and shrubbery had the lowest soil PAH contents. The average PAH-homologue concentrations ranked as follows: 5-rings $\gg$ 3-rings, 4-rings > 6-rings $>$ 2-rings. Much higher concentrations of PAHs were found in the southern part of the sampling area, perhaps due to deposition of airborne particles by the southeasterly winds in winter and spring. We conclude that the small smelting furnaces were the dominant source of PAHs that accumulated in the soils and the southeasterly winds led to the spatial distribution of PAHs in the topsoils. Land vegetation cover and soil utilization patterns also affected the accumulation and distribution of soil PAHs.
\end{abstract}

\section{Introduction}

Natural sources of xenogenetic PAHs include biosynthesis activity and natural fires, but anthropogenic combustion activities are a major source of PAHs in the soils of industrialized countries via atmospheric deposition (Wilson \& Jones 1993). Numerous studies on agricultural (Maliszewska-Kordybach 1996; Manz et al. 2001) and forest soils (Matzner 1984; Aamot et al. 1996; Wenzel et al. 2002) have concluded that anthropogenic PAHs predominate in temperate and tropical regions (Wilcke et al. 1999). Anthropogenic PAHs are emitted from most combustion sources such as industrial manufacturing, vehicle emissions, and waste incineration (Bjørweth \& Ramdahl 1985a).

Dry or wet atmospheric deposition is the main input of semi-volatile organic compounds to soils (Tremolada et al. 1996). PAHs containing two to seven aromatic rings are associated with soots in the flue gases from combustion, incineration, and other high-temperature processes. Most anthropogenic PAHs are produced from high-temperature industrial activities, and can be found in the air, water, sediments, and soils and may eventually reach humans through the food chain or by inhalation. About $17 \%$ and $54 \%$ of the total PAH emissions have been estimated to be from aluminum smelting processes in the USA and Norway, respectively 
(Bjørweth \& Ramdahl 1985b). PAHs are rarely encountered alone in the environment and many interactions occur within a mixture of PAHs whereby the potency of known genotoxic and carcinogenic PAHs can be enhanced (Kaiser 1997).

China is in the early stages of industrialization and the Yangtze River Delta in Southeast China is the most rapidly developing area (Zhao \& Luo 2000). Many privately owned and so-called township enterprises have been established over the last 20 years in rural locations, specializing in metal smelting, production of construction materials, and paper manufacture. Many of these small enterprises operate inefficiently and emit large amounts of gaseous, liquid and solid wastes to the environment (Zhao \& Dong 1996; Zhao \& Luo 2000).

There have been no published studies of organic pollutants such as PCBs and PAHs in the Yangtze Delta region. The objectives of the present study were to obtain detailed information on the spatial distribution of soil PAHs in a typical area where smelting furnaces are the main source of airborne particles and to investigate the relationship between current soil PAHs levels and land use patterns in an attempt to identify the main factors affecting soil PAH accumulation and distribution.

\section{Materials and methods}

\section{The sampling area}

The climate of the Yangtze Delta is subtropical, with annual average rainfall of $1442 \mathrm{~mm}$ and air temperature of $16.1^{\circ} \mathrm{C}$. The soils are Stagnic Anthrosols and Agri-Udic Ferrosols. The sampling area was a valley surrounded by low hills and with most of the land used for cultivation of crops. Soil on the slopes of the hills were mainly uncultivated and were covered by low trees and shrubs. The categories of land use pattern were therefore cultivated drylands, paddy fields, wastelands, woods and shrubbery, and 'other,' i.e. land of which the utilization pattern could not be judged. There were 15 copper- and zinc-smelting furnaces in the area.

\section{Sample collection and storage}

A total of 65 samples were collected from the area in July 2003. Most samples were taken from the flat area in the valley, and the remainder were taken from the neighboring slopes of the surrounding hills. The sampling sites were evenly distributed in the valley. Soil samples were collected from the surface layer $(0-20 \mathrm{~cm})$, airdried indoors, homogenized, passed through a 2-mm sieve and stored in plastic bottles.

\section{Reagents and glassware}

Acetonitrile and cyclohexane were HPLC grade (Tedia Company, USA). All other solvents and chemicals were high purity analytical grade and the solvents were distilled before use. Glassware was cleaned and washed first with detergent, running water and deionized water, heated to dryness, and washed with methanol before use.

\section{Extraction of soil PAHs}

Soil PAHs were extracted with dichloromethane ( $5 \mathrm{~g}$ dry soil with $20 \mathrm{~mL}$ dichloromethane) with ultrasound for $2 \mathrm{~h}$ below $40^{\circ} \mathrm{C}$, and centrifuged, and $5 \mathrm{~mL}$ of the supernatant solution was evaporated. The remainder was then dissolved with $2 \mathrm{~mL}$ of cyclohexane, and $0.5 \mathrm{~mL}$ of the solution was added to a silica gel column and eluted with a mixture of $n$-hexane/dichloromethane $(1: 1 \mathrm{v} / \mathrm{v})$. Two milliliter of the eluent was collected after the first $1 \mathrm{~mL}$ was discarded. The $2 \mathrm{~mL}$ solution was blown dry with nitrogen and dissolved in acetonitrile. This method gave a recovery of $80-96 \%$.

\section{Analysis of PAHs}

Quantitative analysis of the soil extracts was performed by gas chromatography. Concentrations were determined for 16 PAHs in all samples, namely Naphthalene (Nap), Acenaphthylene (AcPy), Acenaphthene (Acp), Fluorene (Flu), Phenanthrene (PA), Anthracene (Ant), Fluoranthrene (FL), Pyrene (Pyr), Chrysene (CHR), Benzo(a)anthracene (BaA), Benzo(b)fluoranthene (BbF), Benzo(k)fluoranthene $(\mathrm{BkF})$, Benzo(a)pyrene $(\mathrm{BaP})$, Indeno[1,2,3,-cd]pyrene (IND), Dibenzo[a, h]anthrecene (DBA), Benzo(g, h, I)perylene (BghiP).

The analysis was conducted using an Agilent 6890 GC equipped with a flame ionization detector (FID) (Agilent Technology). The GC had an autosampler. A $30 \mathrm{~m} \times 0.25 \mathrm{~mm}$ i.d. $\times 0.25 \mu \mathrm{m}$ film thickness HP-5 capillary column (Agilent Technology) was used. The GC temperature was 
programmed from an initial $80{ }^{\circ} \mathrm{C}$ for $1 \mathrm{~min}$, $25^{\circ} \mathrm{C} \mathrm{min}{ }^{-1}$ ramp to $160{ }^{\circ} \mathrm{C}$, and $3{ }^{\circ} \mathrm{C} \mathrm{min}{ }^{-1}$ ramp to $300{ }^{\circ} \mathrm{C}$ which was held for $2 \mathrm{~min}$. Nitrogen was used as the carrier gas with a flow rate of $1.6 \mathrm{~mL} \mathrm{~min}^{-1}$ at a pressure of $8.51 \mathrm{psi}$. A $2.0-\mu \mathrm{L}$ aliquot of the extract was injected while the injector port was held at $280{ }^{\circ} \mathrm{C}$ and operated in splitless mode at a flow rate of $1.0 \mathrm{~mL} \mathrm{~min}{ }^{-1}$. Table 1 shows the limit of detection of the chosen method.

\section{Results}

\section{PAHS}

The lowest concentrations of the 16 individual PAHs in all soil samples were all $0 \mu \mathrm{g} \mathrm{kg}^{-1}$ soil. Among all the $16 \mathrm{PAHs}$, average soil concentrations of Nap, Acp, Flu, FL, Pyr, CHR, DBA and BghiP were less than $1 \mu \mathrm{g} \mathrm{kg}^{-1}$ soil and those of $\mathrm{BaA}, \mathrm{BbF}, \mathrm{BkF}, \mathrm{BaP}$ and IND were greater than $2 \mu \mathrm{g} \mathrm{kg}^{-1}$ soil. Soil concentrations of most PAHs showed great variation with $\mathrm{CV}$ greater than $200 \%$, except AcPy, Flu, BaA and BaP (Table 2).

Total concentrations of PAHs in individual samples ranged from 0 to $530 \mu \mathrm{g} \mathrm{kg}^{-1}$, with an average concentration of $33.0 \pm 64.0 \mu \mathrm{g} \mathrm{kg}^{-1}$. More than $90 \%$ of the samples had a total PAH concentration of $>10 \mu \mathrm{g} \mathrm{kg}^{-1}$ (Figure 1).

Among all the PAH homologues, 5-ring PAHs had the highest average concentration in soils, and their deviation among all the samples was also the smallest. Two-ring PAHs (Nap) had the lowest average concentrations, followed by 6-ring, and concentrations of 3- and 4-ring homologues were similar. Five-ring PAHs amounted to $62.9 \%$ of the total PAHs in soil.

Table 1. Limits of detection (LODs) for 16 PAHs under chosen conditions by GC-FID ( $\left.\mathrm{mg} \mathrm{L}^{-1}\right)$.

\begin{tabular}{llllll}
\hline Analyte & $\begin{array}{l}\text { LOD } \\
\left(\mathrm{mg} \mathrm{L}^{-1}\right)\end{array}$ & Analyte & $\begin{array}{l}\text { LOD } \\
\left(\mathrm{mg} \mathrm{L}^{-1}\right)\end{array}$ & Analyte & $\begin{array}{l}\text { LOD } \\
\left(\mathrm{mg} \mathrm{L}^{-1}\right)\end{array}$ \\
\hline Nap & 0.10 & $\mathrm{BbF}$ & 0.30 & Ant & 0.12 \\
AcPy & 0.05 & $\mathrm{BaP}$ & 0.50 & $\mathrm{FL}$ & 0.14 \\
Acp & 0.06 & IND & 0.60 & $\mathrm{Pyr}$ & 0.13 \\
Flu & 0.04 & DBA & 0.50 & $\mathrm{BaA}$ & 0.14 \\
PA & 0.12 & BghiP & 0.40 & & \\
CHR & 0.14 & BkF & 0.30 & & \\
\hline
\end{tabular}

\section{Soil PAHs and land use patterns}

There was obvious difference in average soil PAH concentrations among the different land use categories. Uncultivated wasteland had the highest concentrations of 9 PAHs (AcPy, Acp, PA, Ant, FL, Pyr, CHR, BaP and IND), PAHs in soil under woods and shrubs was lowest or one of the lowest for 13 PAHs except FL, Ant and PA. DBA and BhgiP were found only in paddy fields and woods and shrubbery soils while, on the other hand, Pry and CHR occurred only in dry land and wasteland soils (Figure 2). The uncultivated wasteland soil had the highest concentrations of 3-, 4- and 5-ring PAHs among all the land use categories (Figure 3).

\section{Concentrations of soil PAHs in different parts of the sampling area}

The sampling area was divided into southern and northern parts at latitude $29^{\circ} 56^{\prime} 21^{\prime \prime} \mathrm{N}$, with 35 of the sampling sites lying in the southern part and 30 in the northern part. Figure 4 shows the averages of different PAH concentrations in these two parts. All 16 PAHs had higher concentrations in the southern part of the area.

Figure 5 shows the average concentrations of the 16 PAHs in the eastern and western parts of the sampling area (divided at longitude $119^{\circ} 55^{\prime} 16^{\prime \prime} \mathrm{E}$ ). A total of 28 of the 65 sampling sites were in the eastern part and the other 37 in the western part. Ten of the 16 PAHs had higher concentrations in the western part.

\section{Effects of furnaces and road transport on accumulation of PAHs in soil}

Sampling sites were divided into three groups according to their distances from furnaces, and more PAHs accumulated in samples collected $<250 \mathrm{~m}$ from the furnaces (Figure 6). When sampling sites less than $250 \mathrm{~m}$ from the road were included in the first group $(<250 \mathrm{~m})$, the trend became less obvious.

\section{Discussion}

The smelting furnaces in the valley are the principal source of PAHs in the study area. Although there are two roads in the valley, they are both 
Table 2. Average concentrations of $16 \mathrm{PAHs}$ in soils in a valley in southeast China ( $\mu \mathrm{g} \mathrm{kg}^{-1} \mathrm{dry}$ soil).

\begin{tabular}{|c|c|c|c|c|c|}
\hline & $\operatorname{Max}\left(\mu \mathrm{g} \mathrm{kg}^{-1}\right)$ & $\operatorname{Min}\left(\mu \mathrm{g} \mathrm{kg}^{-1}\right)$ & Mean $\left(\mu \mathrm{g} \mathrm{kg}^{-1}\right)$ & $\mathrm{SD}\left(\mu \mathrm{g} \mathrm{kg}^{-1}\right)$ & $\mathrm{CV}(\%)$ \\
\hline \multicolumn{6}{|l|}{$P A H$} \\
\hline Naphthalene (Nap) & 5.62 & nd & 0.36 & 0.82 & 228 \\
\hline Acenaphthylene (AcPy) & 8.11 & nd & 1.07 & 1.29 & 120 \\
\hline Acenaphthene (Acp) & 13.9 & nd & 0.84 & 2.02 & 241 \\
\hline Fluorene (Flu) & 1.85 & nd & 0.24 & 0.39 & 160 \\
\hline Phenanthrene (PA) & 41.6 & nd & 1.63 & 5.08 & 311 \\
\hline Anthracene (Ant) & 35.1 & nd & 1.29 & 4.47 & 347 \\
\hline Fluoranthrene (FL) & 48.7 & nd & 0.99 & 6.03 & 610 \\
\hline Pyrene (Pyr) & 7.11 & nd & 0.16 & 0.91 & 561 \\
\hline Chrysene (CHR) & 24.9 & nd & 0.32 & 3.24 & 629 \\
\hline Benzo(a)anthracene (BaA) & 15.3 & nd & 4.43 & 2.00 & 73 \\
\hline Benzo(b)fluoranthene $(\mathrm{BbF})$ ) & 49.1 & nd & 2.72 & 6.97 & 256 \\
\hline Benzo(k)fluoranthene (BkF) & 36.3 & nd & 2.09 & 5.25 & 251 \\
\hline Benzo(a)pyrene $(\mathrm{BaP})$ & 86.1 & nd & 7.51 & 10.4 & 139 \\
\hline Indeno[1,2,3,-cd]pyrene (IND) & 163.6 & nd & 8.27 & 19.8 & 240 \\
\hline Dibenzo[a,h]anthrecene (DBA) & 6.33 & nd & 0.27 & 1.24 & 459 \\
\hline Benzo(g,h,I)perylene (BghiP) & 50.6 & nd & 0.99 & 6.36 & 641 \\
\hline \multicolumn{6}{|l|}{ PAH-homologue } \\
\hline 2-ring & 5.62 & nd & 0.36 & 0.82 & 227 \\
\hline 3-ring & 96.4 & nd & 5.08 & 11.7 & 230 \\
\hline 4-ring & 96.0 & nd & 5.90 & 11.6 & 196 \\
\hline 5-ring & 335 & nd & 20.9 & 40.7 & 195 \\
\hline 6-ring & 50.6 & nd & 0.99 & 6.36 & 641 \\
\hline
\end{tabular}

minor roads and the effect of traffic on soil PAH accumulation is therefore small. Studies in the United States have indicated that motor vehicles account for approximately $36 \%$ of the yearly total PAHs (Benner et al. 1989), perhaps because the atmospheric emissions from industrial chimneys were cleaner and the road traffic was heavier compared with the present study.
There is considerable summer and autumn rainfall in the valley with little wind (except typhoons). Thus during these two seasons, wind plays less important role in the dispersion of soot particles from the furnaces. The prevailing southerly wind in winter and spring carries more PAHs to the southern part of the valley.

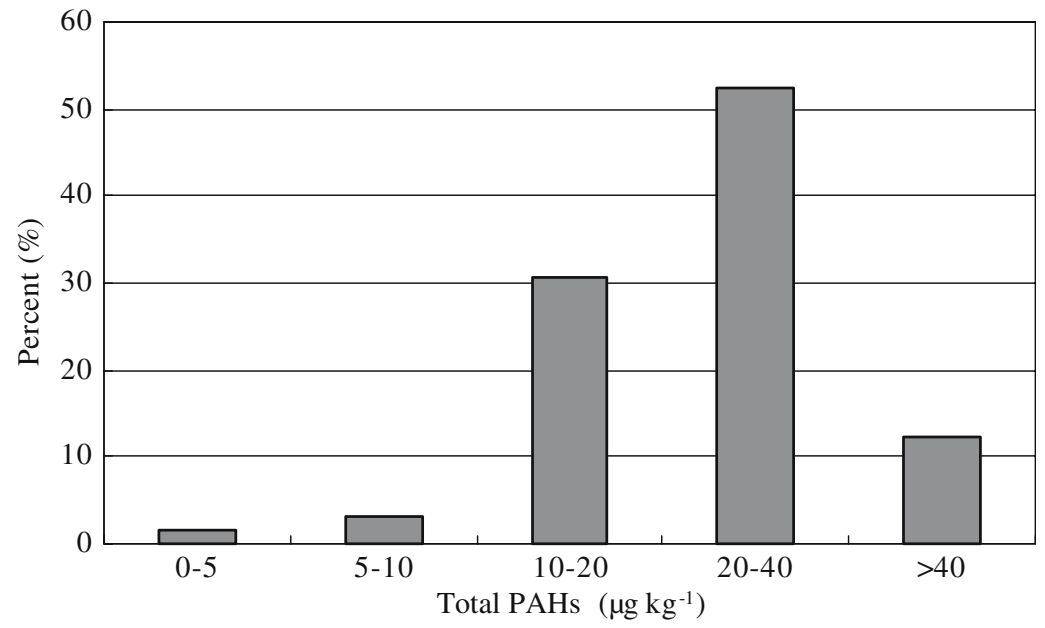

Fig. 1. Percentage of the total PAHs concentration in 65 soil samples. 


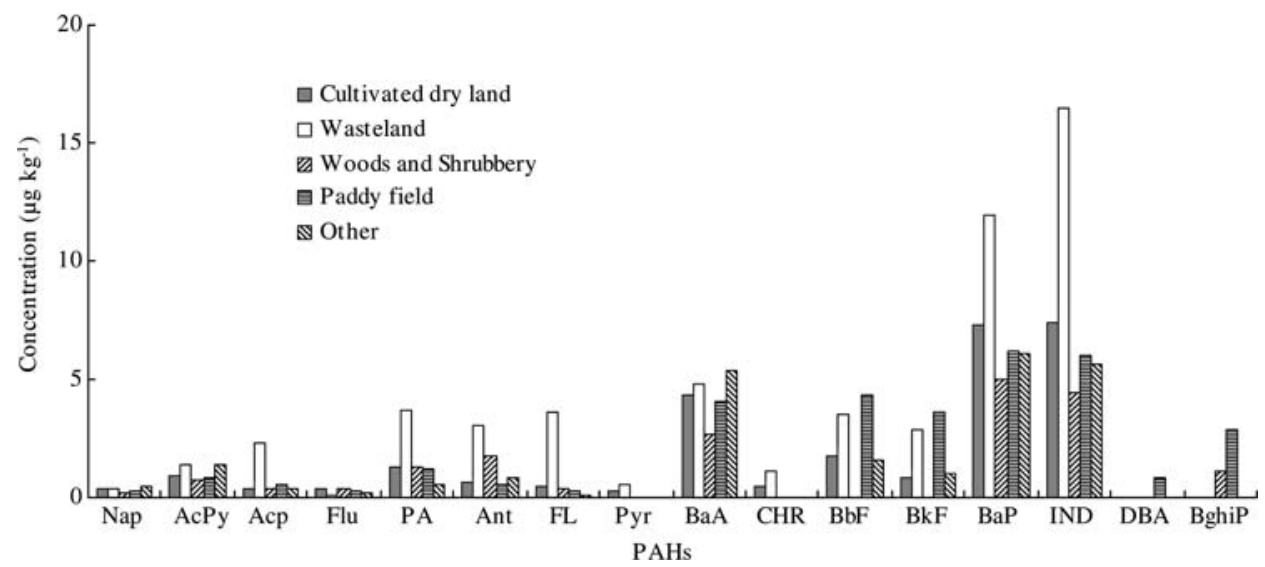

Fig. 2. Soil PAHs concentration under different utilizations.



Fig. 3. PAH-homologue in soils with different utilization patterns.

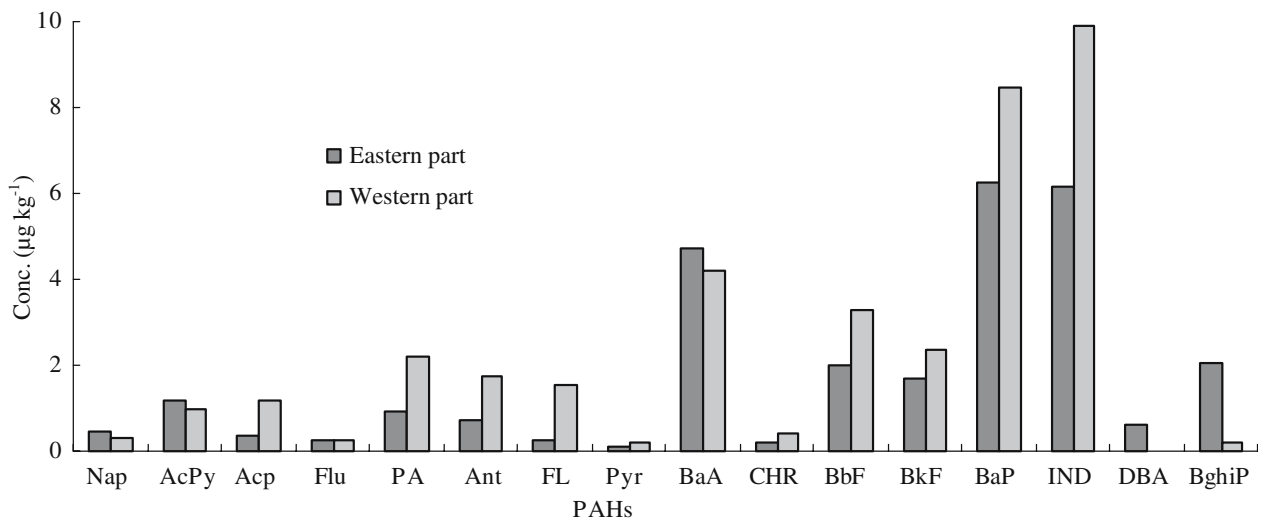

Fig. 4. Average concentrations of 16 PAHs in southern and northern parts of the sampled area. 


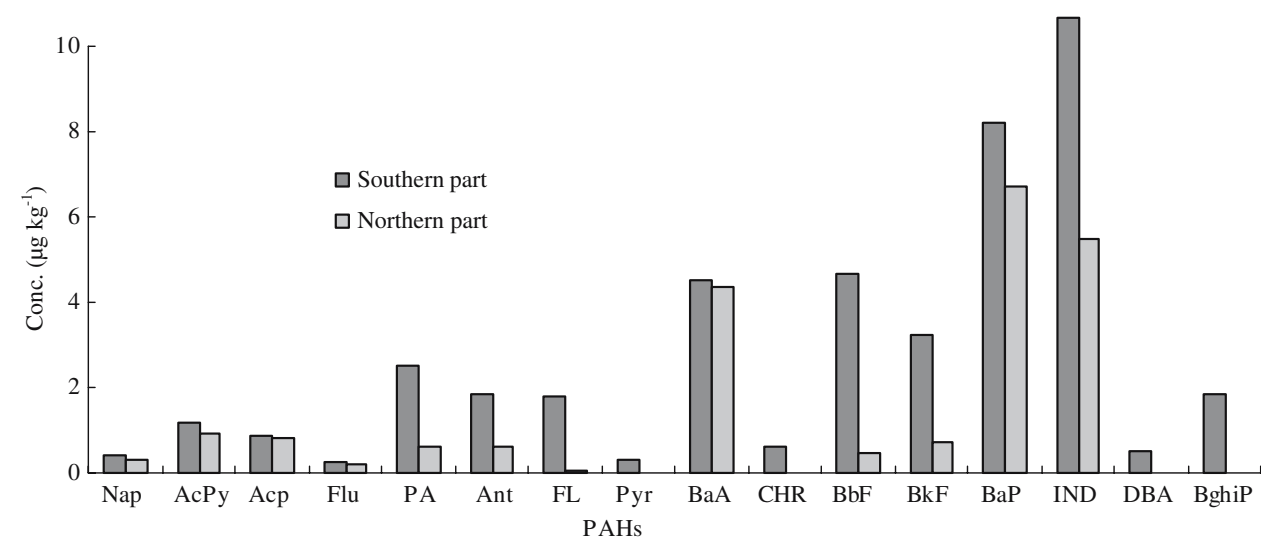

Fig. 5. Average concentrations of $16 \mathrm{PAHs}$ in eastern and western parts of the sampled area.

More PAHs were found in the western part of the valley. One possible explanation is that the valley lies in a south-north direction, and this makes the north-south wind more important, with more PAH-laden particles transported to the southern part. Another factor is the larger number of furnaces in the western part (eight compared with seven in the east).

Judging from Figure 6, many more particles precipitated within less than $250 \mathrm{~m}$ of the furnaces, with smaller differences in most PAHs being found between sites $250-500 \mathrm{~m}$ and $>500 \mathrm{~m}$ from the furnaces.

Five-ring compounds were the dominant PAHs in the sampling area. Less 6- and 2-ring PAHs were detected in the area. The persistence of PAHs is strongly affected by the number of rings, with PAHs with more rings more difficult to degrade (Cerniglia 1992), evaporate or be absorbed by plants. This is reflected by the increasing concentrations of 2-, 3-, 4- and 5-ring
PAHs. The soil quality criteria of $\mathrm{BaP}$ and total PAHs in Denmark are 0.1 and $5 \mathrm{mg} \mathrm{kg}^{-1}$ dry weight, respectively (Samsoe-Petersen et al. 2002). Based on these criteria, the total PAHs and $\mathrm{BaP}$ concentration of all the 65 samples were below the standard. Stalikas et al. (1997) investigated the concentration of PAHs in soil near a lignite-fired power plant in Greece and found enriched PAHs concentrations in soil and attributed this to lignite combustion, but the PAHs were still under the critical values for agricultural cultivation.

PAHs in soil in the industrialized area are still in the safe range. However, soot from the smelting furnaces may contain total PAHs as high as over $30 \mathrm{~g} \mathrm{~kg}^{-1}$ dry weight (Wei 1996), and this represents a potential threat to human health. Humans may absorb more PAH-containing particles by inhalation, and skin exposure to these materials may also result in health problems (Sheu et al. 1997).

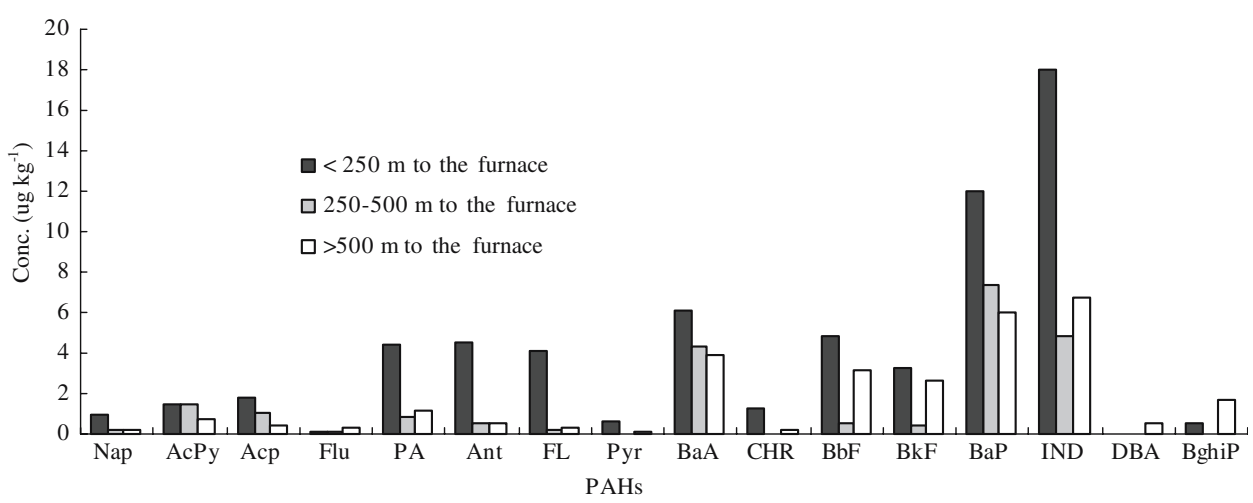

Fig. 6. Concentration of PAHs at sites with different distance from the furnaces $(1,<250 \mathrm{~m} ; 2,250-500 \mathrm{~m} ; 3,>500 \mathrm{~m})$. 
The type of land use influences the PAH concentrations and accumulation patterns in soil (Wilcke 2000). Arable soils often have low concentrations of PAHs because of the dilution effect by plowing (Bierl et al. 1984; Brüne 1986). Soil disturbance may also help to increase PAH bioavailability, and exposure of the subsoil to sunlight may increase degradation of the pollutants by photolysis. In permanent grassland soil, the accumulation of PAHs may be more significant because of the lack of plowing preventing dilution (Brüne 1986). Better water conditions are beneficial to the dissipation of PAHs (Labare \& Alexander 1995; Doick and Semple 2003), but this trend is not very obvious in the present study.

Our finding that PAH concentrations in soils under woods and shrubs was much lower than in wasteland and more than that of cultivated dry land soil is different from the results of other studies (Matzner 1984). Differences in soil PAH distribution among different land use types may be result from the short exposure history of the soil to the emission sources. Most of the small-scale enterprises in the study area appeared after the 1980s. Thus the accumulation of PAHs in soils may be different from that in United States and other countries with a longer history of PAH emissions. In addition, the land use patterns in the study area are constantly changing. For example, some of the so-called wastelands in this study were originally agricultural fields that were degraded by the establishment of factories and they do not show similar PAH accumulation patterns to those in industrialized countries. Changing land use patterns result in emissions of PAHs being dynamic processes that require more detailed study in the long term.

\section{Conclusions}

Accumulation of PAHs in topsoils $(0-20 \mathrm{~cm})$ was investigated in a valley with 15 smelting furnaces in the Yangtze Delta region in Southeast China. The sum of 16 PAHs concentration ranged from 0 to $530 \mu \mathrm{g} \mathrm{kg}^{-1}$, with an average value of $33.2 \mu \mathrm{g} \mathrm{kg}^{-1}$, and more than $80 \%$ of the sampling sites contained less than $40 \mu \mathrm{g} \mathrm{kg}^{-1}$ total PAHs. Five-ring PAHs made up the largest proportion of all the PAHs, while 2- and 6-ring PAHs were the lowest. Higher soil concentration of PAHs were found in southern part of the north-south oriented valley and in soils collected near the smelting furnaces. More PAHs were found in uncultivated wasteland soils and soils under woods and shrubs contained less PAHs. The smelting furnaces were the main source of soil PAHs in the valley.

\section{Acknowledgements}

We thank the National Science Foundation of China (No. 40031010) and the Major State Basic Research and Development Program of the People's Republic of China (2002CB410809/10), the National Science Foundation of China (No. 40432005), Program of Innovative Engineering of the Chinese Academy of Sciences, PR China (KZCX3-SW-429), for generous funding.

\section{References cited}

Aamot E, Steinnes E, Schmid R. 1996 Polycyclic aromatic hydrocarbons in Norwegian forest soils: Impact of long range atmospheric transport. Environ Pollut 92, 275-280.

Benner BA, Gordon GE, Wise SA. 1989 Mobile sources of atmospheric polycyclic aromatic hydrocarbons: A roadway tunnel study. Environ Sci Technol 23, 1269-1277.

Bierl R, Kaaet W, Thomas W. 1984 Spatial and temporal concentration gradients of PAH (fluoranthene, benzo(a)pyrene, gamma-BHC, 2,4-D in samples of soil, soil water, and groundwater in an agricultural research area. Fresen $J$ Anal Chem 319, 172-179.

Bjørweth A, Ramdahl T. 1985a Source and Emissions of PAH. Handbook of Polycyclic Aromatic Hydrocarbons, Vol. 1. New York: Marcel Dekker.

Bjørweth A, Ramdahl T. 1985b Handbook of Polycyclic Aromatic Hydrocarbons, Vol. 2. New York: Marcel Dekker.

Brüne H, 1986. Schadstoffeintrag in Böden durch Industrie. Besiedlung, Verkehr und Landbewirtschaftung. VDLUFASchriftenreihe 16 (Kongreßband, 1985), 85-102.

Cerniglia CE. 1992 Biodegradation of polycyclic aromatic hydrocarbons. Biodegradation 3, 351-368.

Doick KJ, Semple KT. 2003 The effect of soil:water ratios on the mineralisation of phenanthrene: LNAPL mixtures in soil. FEMS Microbiol Lett 220, 29-33.

Kaiser J. 1997 Endocrine disrupters: synergy paper questioned at toxicology meeting. Science 275, 1879-1879.

Labare MP, Alexander M. 1995 Enhanced mineralisation of organic compounds in non-aqueous phase liquids. Environ Toxicol Chem 14, 257-265.

Maliszewska-Kordybach B. 1996 Polycyclic aromatic hydrocarbons in agricultural soils in Poland: preliminary proposals for criteria to evaluate the level of soil contamination. Appl Geochem 11, 121-127.

Manz M, Wenzel KD, Dietze U, Schuurmann G. 2001 Persistent organic pollutants in agricultural soils of central Germany. Sci Total Environ 277, 187-198. 
Matzner E. 1984 Annual rates of deposition of polycyclic aromatic hydrocarbons in different forest ecosystems. Water Air Soil Pollut 21, 425-434.

Samsoe-Petersen L, Larsen EH, Larsen PB, Bruun P. 2002 Uptake of trace elements and PAHs by fruit and vegetables form contaminated soils. Environ Sci Technol 36, 3057-3063.

Sheu HL, Lee WJ, Lin SJ, Fang GC, Chang HC, You WC. 1997 Particle-bound PAH content in ambient air. Environ Pollut 96, 369-382.

Stalikas CD, Chaidou CI, Pilidis GA. 1997 Enrichment of PAHs and heavy metals in soils in the vicinity of the lignitefired power plants of West Macedonia (Greece). Sci Total Environ 204, 135-146.

Tremolada P, Burnett V, Calamari D, Jones KC. 1996 Spatial distribution of PAHs in the UK atmosphere using pine needles. Environ Sci Technol 30, 3570-3577.

Wei YL. 1996 Distribution study of priority pollutant PAHs from a laboratory aluminum can chip smelting furnace. J Hazard Mater 49, 267-280.
Wenzel KD, Manz M, Hubert A, Schuurmann G. 2002 Fate of POPs (DDX, HCHs, PCBs) in upper soil layers of pine forests. Sci Total Environ 286, 143-154.

Wilson SC, Jones KC. 1993 Bioremediation of soil contaminated with polynuclear aromatic hydrocarbons (PAHs): a review. Environ Pollut 31, 229-249.

Wilcke W. 2000 Polycyclic aromatic hydrocarbons (PAHs) in soil - a review. J Plant Nutr Soil Sci 163, 229-248.

Wilcke W, Muller S, Kanchanakool N, Niamskul C, Zech W. 1999 Urban soil contamination in Bangkok: concentrations and patterns of polychlorinated biphenyls (PCBs) in topsoils. Aust J Soil Res 37, 245-254.

Zhao Q, Dong Y. 1996 Problems of agriculture and environment and sustainable development in the Yangtze Delta. Soils 28, 285-289, 310.

Zhao Q, Luo Y. 2000 Advice on carrying out research about quality of resources and environment in the rapidly developing coastal area in Southeast China. Soils 32, 169-172. 